Tadeusz CHMIELNIAK ${ }^{1}$

Pawel PILARZ ${ }^{2}$

\title{
MODELOWANIE NUMERYCZNE ODAZOTOWANIA SPALIN METODĄ SCR
}

\begin{abstract}
Z uwagi na konieczność wprowadzenia od 2016 roku nowych norm emisji tlenków azotu $\left(\mathrm{NO}_{\mathrm{x}}\right)$, należy przeanalizować możliwości wykorzystania technologii selektywnej redukcji katalitycznej (SCR) jako uzupełnienie metod pierwotnych. Zastosowanie katalizatora jako dodatkowego modułu do oczyszczania spalin z tlenków azotu pozwala na wydłużenie pracy bloków węglowych uwzględniając założenia Dyrektywy IED. Redukcja tlenków azotu ze spalin metodą SCR zachodzi poprzez wtrysk reagenta (amoniaku, wody amoniakalnej) w kanale spalinowym oraz reakcje konwersji $\mathrm{NO}_{\mathrm{x}}$ na powierzchni katalizującej. Praca ta jest oparta na modelowaniu przepływu spalin przez kanały o różnej geometrii za pomocą kodu AnsysFluent. Jest to pierwszy etap tworzenia pełnego modelu CFD dla technologii SCR, w którym skupiono się na wpływie średnicy kanałów katalizatora na przepływ spalin.
\end{abstract}

Słowa kluczowe: geometria kanałów, katalizator, model $\mathrm{CFD}$, redukcja $\mathrm{NO}_{\mathrm{x}}$.

\section{Wprowadzenie}

\subsection{Uwarunkowania emisyjne dla bloków węglowych}

Instalacje energetycznego spalania węgla przyczyniają się do przemysłowych emisji zanieczyszczeń gazowych $\left(\mathrm{SO}_{2}, \mathrm{NO}_{\mathrm{x}}\right)$, pyłowych oraz odpadów ściekowych wprowadzanych do środowiska. $Z$ uwagi na dbałość o środowisko i zdrowie społeczeństwa wprowadza się normy ograniczające emisję niekorzystnych dla otoczenia substancji. Zawartość tlenków azotu $\left(\mathrm{NO}_{\mathrm{x}}\right)$ oraz dwutlenku siarki są ustalone wg Dyrektyw oraz krajowych rozporządzeń dotyczących ochrony środowiska. Istotnym dokumentem $\mathrm{w}$ przeciągu kilku najbliższych lat jest Dyrektywa 2010/75/UE (IED) z dnia 24 listopada 2010 r. w sprawie emisji przemysłowych, która obejmuje obszar regulowany dotych-

\footnotetext{
${ }^{1}$ Tadeusz Chmielniak, Politechnika Śląska w Gliwicach, ul. Konarskiego 18, e-mail: tadeusz.chmielniak@ polsl.pl

${ }^{2}$ Autor do korespondencji: mgr inż. Paweł Pilarz, Politechnika Śląska w Gliwicach, ul. Konarskiego 18, tel.: 32-237-22-14,e-mail: pawel.pilarz@polsl.pl
} 
czas przez kilka odrębnych dyrektyw, m.in. dyrektywy LCP (w sprawie emisji zanieczyszczeń z dużych obiektów energetycznego spalania), IPPC (w sprawie zintegrowanego zapobiegania i zmniejszania zanieczyszczeń) oraz dyrektywy o spalaniu odpadów i ograniczaniu emisji lotnych związków organicznych [5].

$\mathrm{W}$ polskiej energetyce utrzymuje się odpowiednie poziomy emisji zgodne z aktualnym rozporządzeniem Ministra Środowiska [8] za pomocą instalacji oczyszczania spalin. W przypadku redukcji $\mathrm{NO}_{\mathrm{x}}$ stosuje się metody pierwotne związane z prowadzeniem procesu spalania paliw w sposób ograniczający tworzenie się tych zanieczyszczeń (spalanie w kotłach fluidalnych, palniki niskoemisyjne, stopniowanie paliwa i powietrza, systemy OFA i SOFA). Jednak od 1 stycznia 2016 r. nastąpi kolejne obniżenie poziomu emisji tlenków azotu co przedstawiono na rys. 1,co może wiązać się z koniecznością modernizacji bloków węglowych (m.in.: OP-650, AP-1650, BB-1150) uwzględniając zastosowanie wtórnych metod redukcji $\mathrm{NO}_{\mathrm{x}}$, w tym selektywnej redukcji katalitycznej (selective catalytic reduction - SCR)[4].

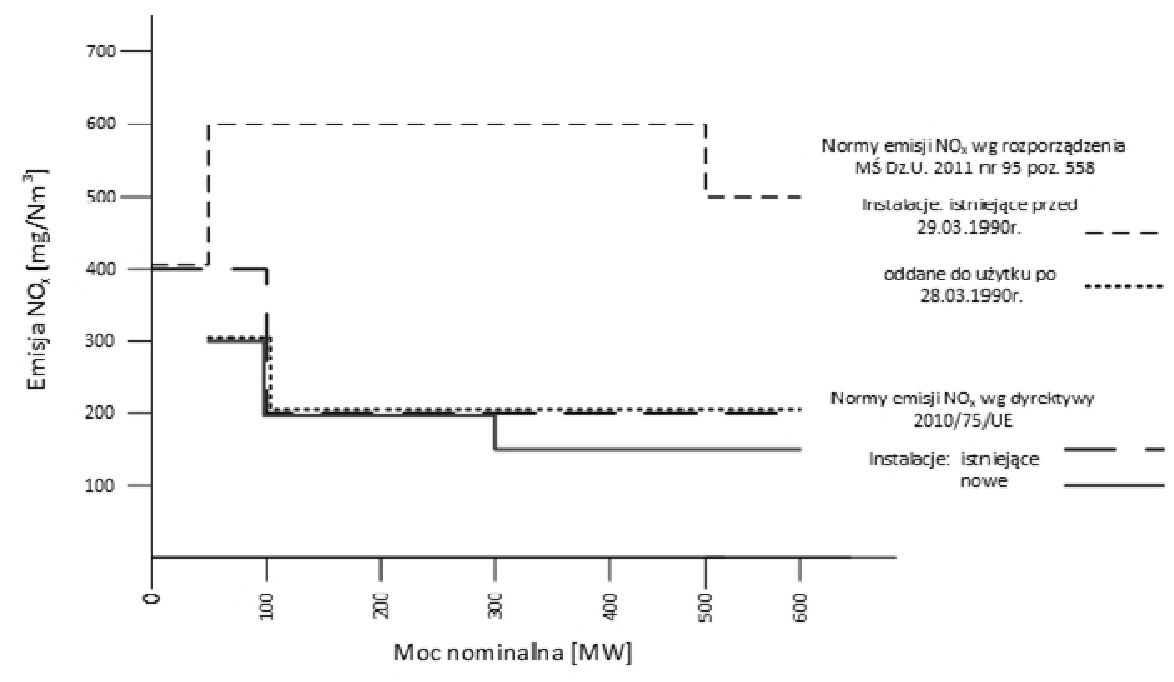

Rys. 1. Normy emisji $\mathrm{NO}_{\mathrm{x}} \mathrm{z}$ instalacji spalających węgiel kamienny [4,9]

Fig. 1. Standards of $\mathrm{NO}_{\mathrm{x}}$ emission from coal-fired installations $[4,9]$

\subsection{Metody redukcji $\mathrm{NO}_{\mathrm{x}}$ ze spalin bloków węglowych}

Wyróżnić można dwa typy metod prowadzących do zmniejszenia stężenia związków azotu w spalinach: pierwotne oraz wtórne. Do metod pierwotnych można zaliczyć modyfikacje prowadzonego procesu spalania m.in. stopniowanie powietrza i paliwa (palniki niskoemisyjne LNB, systemy dysz OFA i SOFA), obniżanie temperatury płomienia (spalanie fluidalne) i zmniejszanie nadmiaru powietrza (recyrkulacja spalin). Wtórne metody redukcji $\mathrm{NO}_{\mathrm{x}}$ skupia- 
ją się na oczyszczaniu spalin poza komorą paleniskową. Spotyka się wiele sposobów odazotowania spalin, m.in. [11]:

- Selektywną redukcję niekatalityczną SNCR,

- Selektywną redukcję katalityczną SCR,

- Absorpcję z utlenianiem,

- Absorpcję wspólną $\mathrm{NO}_{\mathrm{x}}$ i $\mathrm{SO}_{2}$,

- Adsorpcję z wykorzystaniem węgla aktywnego.

\subsection{Selektywna redukcja katalityczna}

Zastosowanie metody SCR pozwala na obniżenie energii aktywacji dla procesu redukcji tlenków azotu przy udziale reagenta $\left(\mathrm{NH}_{3}, \mathrm{NH}_{4} \mathrm{OH}\right)$. Katalizator najczęściej jest zbudowany z monolitu o strukturze plastra miodu, siatki o wydłużonych kanalikach lub płyt ze stali nierdzewnej ułożonych względem siebie równolegle. Umieszczenie na porowatej powierzchni pierwiastków katalizujących (wanadowego, wolframowo-wanadowego lub platynowego) pozwala na obniżenie temperatury procesu redukcji do poziomu $\mathrm{t}=300 \div 400^{\circ} \mathrm{C}$. Wtrysk reagenta następuje odpowiednio wcześniej w kanale doprowadzającym spaliny, który jest zaopatrzony w szereg prowadnic i mieszaczy. Zastosowanie ich gwarantuje optymalne rozprowadzenie stężenia $\mathrm{NO}_{x}$ oraz cząsteczek $\mathrm{NH}_{3}$ w strumieniu spalin przed reaktorem SCR. Reakcje redukcji w module SCR zachodzą wg równań $(1 \div 4)[3,11]$ :

$$
\begin{array}{ll}
6 \mathrm{NO}+4 \mathrm{NH}_{3} \rightarrow 5 \mathrm{~N}_{2}+6 \mathrm{H}_{2} \mathrm{O} & \Delta \mathrm{H}=-300,8 \mathrm{~kJ} / \mathrm{mol} \mathrm{NO} \\
4 \mathrm{NO}+4 \mathrm{NH}_{3}+\mathrm{O}_{2} \rightarrow 4 \mathrm{~N}_{2}+6 \mathrm{H}_{2} \mathrm{O} & \Delta \mathrm{H}=-406,1 \mathrm{~kJ} / \mathrm{mol} \mathrm{NO} \\
6 \mathrm{NO}_{2}+8 \mathrm{NH}_{3} \rightarrow 7 \mathrm{~N}_{2}+12 \mathrm{H}_{2} \mathrm{O} & \Delta \mathrm{H}=-453,0 \mathrm{~kJ} / \mathrm{mol} \mathrm{NO} \\
2 \mathrm{NO}_{2}+4 \mathrm{NH}_{3}+\mathrm{O}_{2} \rightarrow 3 \mathrm{~N}_{2}+6 \mathrm{H}_{2} \mathrm{O} & \Delta \mathrm{H}=-663,5 \mathrm{~kJ} / \mathrm{mol} \mathrm{NO}
\end{array}
$$

$\Delta \mathrm{H}$ - entalpia ujemna świadczy o egzotermiczności reakcji

W wyniku działania katalizatora SCR otrzymuje się znacznie zredukowany poziom stężenia tlenków azotu, na rzecz tworzenia się cząsteczek obojętnych dla środowiska tj. azotu i wody. Ten proces jest traktowany jako Best Available Technology - BAT, czyli jedna z najlepszych technik oczyszczania spalin wykazująca się bezodpadowością. W celu zachowania optymalnego stopnia przereagowania $\mathrm{NO}_{x}$ z $\mathrm{NH}_{3}$ najważniejszym jest zapewnienie odpowiedniej temperatury procesu oraz wtrysk $\mathrm{w}$ strumień spalin stosowniej ilości reagenta. W przeciwnym wypadku istnieje możliwość wylotu nieprzereagowanego amoniaku ze strumieniem spalin. Tą metodę wykorzystano przy modernizacji bloków typu 200 MW w Elektrowni Łaziska [7]. 


\subsection{Lokalizacja katalizatora SCR}

Chęć zastosowania metody SCR jako głównej techniki redukcji $\mathrm{NO}_{x}$ prowadzi do uwzględnienia dla niej miejsca już na etapie projektowania bloku węglowego. W przypadku istniejących instalacji spalania węgla konieczna może być znaczna ingerencja w konstrukcję ciągu technologicznego oczyszczania spalin. Można wyróżnić kilka miejsc najczęściej wybieranych jako lokalizacje katalizatora:

- High-dust SCR - redukcja $\mathrm{NO}_{\mathrm{x}}$ ze spalin zapylonych,

- Low-dust $\mathrm{SCR}$ - redukcja $\mathrm{NO}_{\mathrm{x}}$ ze spalin odpylonych,

- Low-dustTail-end SCR - deNO $\mathrm{x}_{\mathrm{x}}$ spalin odpylonych i odsiarczonych.

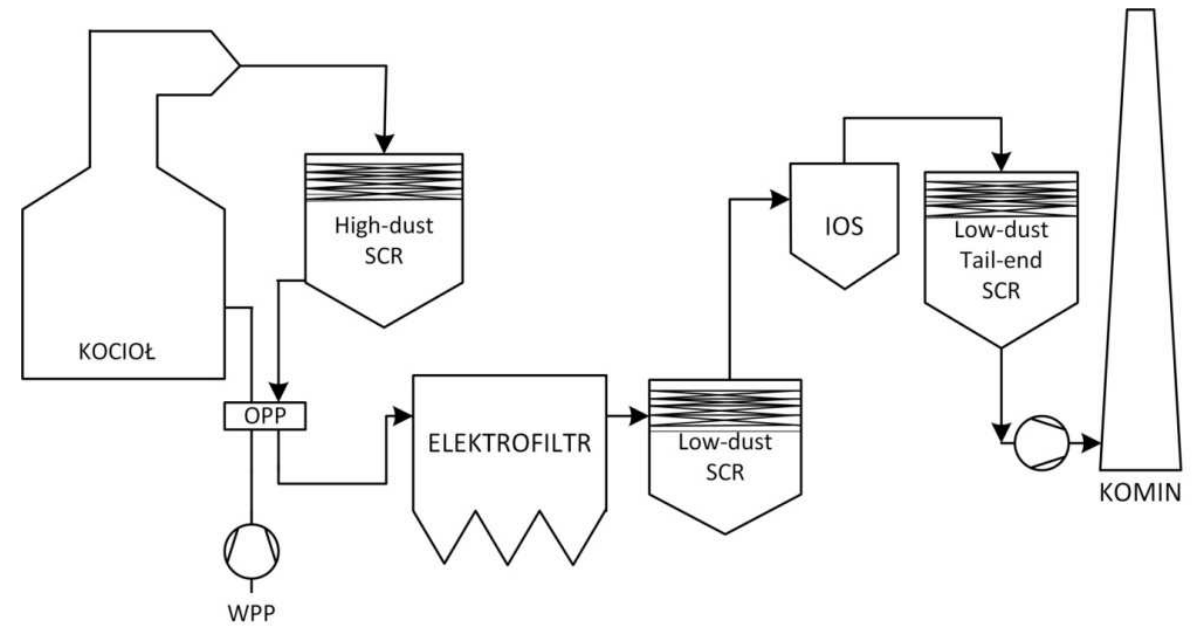

Rys. 2. Możliwe miejsca instalacji katalizatora SCR

Fig. 2. Possible position ofSCR catalyst installation

Reaktor SCR typu high-dust instaluje się w drugim ciągu kotła w rejonie podgrzewacza wody (rys. 2). Z uwagi na różny rozkład temperatur spalin konieczna może być przebudowa ciągu, w tym rozdzielenie podgrzewacza na rzecz instalacji warstw katalizatora, stosowanie dodatkowych układów odprowadzania pyłu oraz zmianę ułożenia kanałów powietrza pierwotnego i spalin. SCR instaluje się najczęściej w postaci dwóch warstw przedzielonych wolną przestrzenią, która pozwala na prowadzenie prac remontowych oraz możliwość wprowadzenia kolejnej warstwy katalizującej[2].

Zbyt wysoka temperatura oraz zapylenie spalin mogą powodować spiekanie oraz erozję powierzchni reaktora SCR obniżając wydajność procesu redukcji $\mathrm{NO}_{\mathrm{x}}$. Aby odseparować większe ziarna pyłu stosuje się nawrót spalin i ekrany tzw. Large Particle Ash screen o otworach nieznacznie mniejszych niż wymiar kanałów katalizatora. Ekrany są zbudowane ze stali nierdzewnej lub 
węglowej odpowiednio zabezpieczonej węglikiem wolframu podnoszącym ich wytrzymałość. To rozwiązanie pozwala ochronić SCR przed popiołem, wydłużając żywotność modułów reaktora oraz zapewniając wydajność redukcji $\mathrm{NO}_{\mathrm{x}}[10]$.

SCR typu low-dust polega na instalacji katalizatora za elektrofiltrem. Rozwiązanie to jest stosowane po uwzględnieniu optymalnej temperatury oraz wysokiego zapylenia spalin. W przypadku high-dusti low-dust występuje problem konwersji dwutlenku siarki zawartego w spalinach. $\mathrm{SO}_{2}$ reaguje na powierzchni katalizatora utleniając się i reagując $\mathrm{z} \mathrm{NH}_{3}(5 \div 7)$ [6]:

$$
\begin{aligned}
& \mathrm{SO}_{2}+1 / 2 \mathrm{O}_{2} \rightarrow \mathrm{SO}_{3} \\
& \mathrm{SO}_{3}+2 \mathrm{NH}_{3}+\mathrm{H}_{2} \mathrm{O} \rightarrow\left(\mathrm{NH}_{4}\right)_{2} \mathrm{SO}_{4} \\
& \mathrm{SO}_{3}+\mathrm{NH}_{3}+\mathrm{H}_{2} \mathrm{O} \rightarrow \mathrm{NH}_{4} \mathrm{HSO}_{4}
\end{aligned}
$$

Konwersja $\mathrm{SO}_{2} / \mathrm{SO}_{3}$ prowadzi do powstawania soli nieorganicznych, które zanieczyszczają powierzchnię katalizującą, ograniczając skuteczność redukcji tlenków azotu. Według [5] wzrost temperatury spalin w katalizatorze powyżej $380^{\circ} \mathrm{C}$ prowadzi do konwersji $1,8 \%$ całości dwutlenku siarki, natomiast przy temperaturze $420^{\circ} \mathrm{C}$ stopień konwersji wzrasta do $5 \%$.

Instalacja typulow-dusttail-end SCR służy do redukcji $\mathrm{NO}_{\mathrm{x}}$ ze spalin odpylonych oraz pozbawionych związków siarki. Katalizator w tym wariancie znajduje się za elektrofiltrem i instalacją odsiarczania (IOS), co przynosi korzyści w postaci ograniczenia erozji warstw reaktora. Uzyskuje się również mniejszy spadek wydajności procesu deNO$_{x}$ i minimalizację problemu konwersji $\mathrm{SO}_{2} / \mathrm{SO}_{3}$. Problemem tego rozwiązania jest zbyt niska temperatura spalin, która nie pozwala na przeprowadzenie redukcji $\mathrm{NO}_{\mathrm{x}}$ (po odsiarczaniu suchym $t=$ $130 \div 140^{\circ} \mathrm{C}$, po mokrym $t=60^{\circ} \mathrm{C}$ ). Dlatego też wymagana jest instalacja dodatkowego palnika gazowego podnoszącego temperaturę spalin oraz wymiennika ciepła typu spaliny-spaliny (przed-po SCR)[8].

\section{Model przepływowy katalizatora}

\subsection{Założenia do modelu}

Katalizatory służące do redukcji tlenków azotu ze spalin oferowane przez producentów mają kilka typów przekrojów kanałów. Wyróżnić można m.in. honeycomb, plate i wave. Warstwy katalizatora honeycomb zbudowane są z modułów o stałej wielkości $150 \times 150 \mathrm{~mm}$ oraz długości w zakresie $350 \div 1500 \mathrm{~mm}$. Natomiast średnica kanalików w modułach uwarunkowana jest docelowym zastosowaniem z uwzględnieniem typu spalin. Dla instalacji spalających gaz i paliwa płynne zarezerwowane są przekroje w zakresie $2 \div 6 \mathrm{~mm}$, 
natomiast dla bloków węglowych stosuje się zakres $5 \div 10 \mathrm{~mm}$, w zależności od stopnia zapylenia oczyszczanego z $\mathrm{NO}_{x}$ gazu.

Na potrzeby budowy modelu przepływowego przyjęto długość kanałów równą $350 \mathrm{~mm}$, natomiast średnice kanałów: $5,2 \mathrm{~mm}, 5,8 \mathrm{~mm}, 6,1 \mathrm{~mm}, 7,2 \mathrm{~mm}$, $8,0 \mathrm{~mm}$ oraz $8,3 \mathrm{~mm}$, które znajdują zastosowanie w katalizatorach deNO $\mathrm{N}_{\mathrm{x}}$ bloków węglowych. Prędkość strumienia spalin założono na poziomie $v_{\text {in }}=10 \mathrm{~m} / \mathrm{s}$. Przypadek zamodelowano za pomocą AnsysFluent [1] i jest to pierwszy etap w procesie numerycznego modelowania procesu redukcji tlenków azotu ze spalin za pomocą katalizatora SCR.

Celem prowadzenia obliczeń numerycznych jest zbadanie wpływu średnicy kanałów katalizatora na przepływ strugi spalin, uwzględniając zmianę ciśnienia, zmianę prędkości oraz intensywność turbulencji. Model geometryczny przedstawiono na rys. 3., natomiast do obliczeń wykorzystano metodę Coupled oraz model turbulencji k-epsilon realizable z opcją standard wallfunctions.

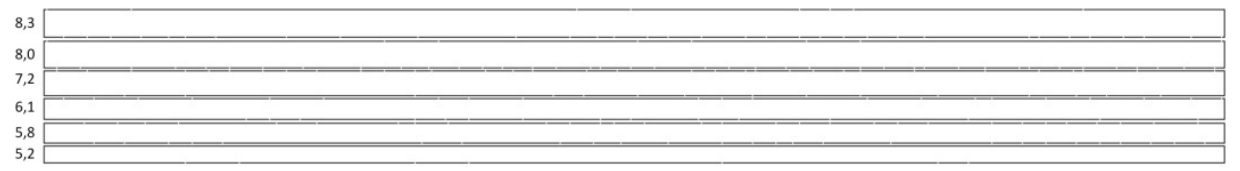

Rys. 3. Model geometryczny kanałów katalizatora

Fig. 3. Geometric model of catalyst channels

\subsection{Wynikimodelowania}

W wyniku przeprowadzonych obliczeń numerycznych w AnsysFluent [1] otrzymano wyniki przedstawiające wpływ średnicy kanału na ciśnienie (rys. 4), prędkość przepływu (rys. 5) oraz energię kinetyczną turbulencji (rys.6).
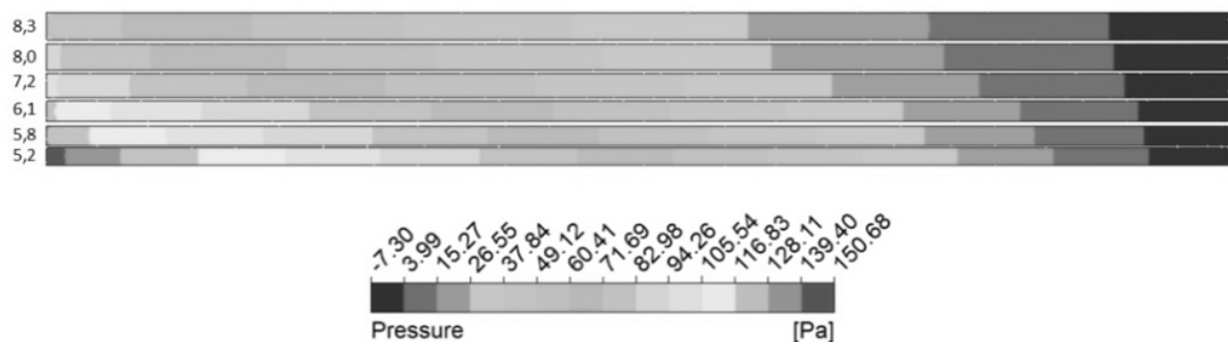

Rys. 4. Ciśnienie statyczne w modelowanych kanałach

Fig. 4. Static pressure in modeled channels 

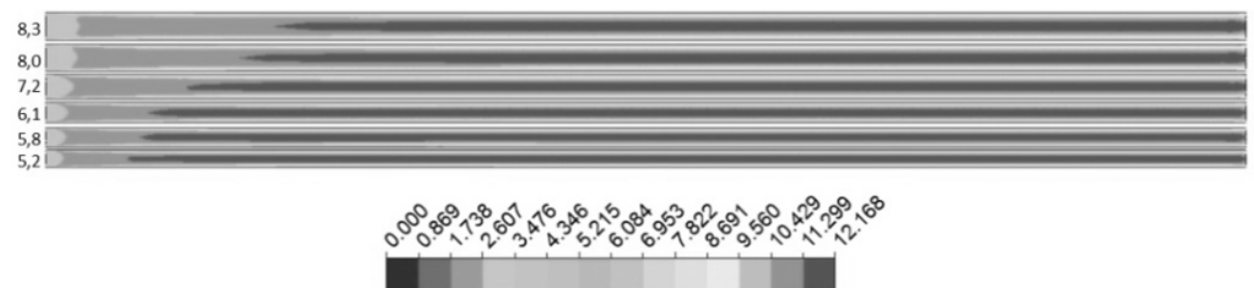

Rys. 5. Prędkość przepływu spalin przez kanały

Fig. 5. The flow rate of the exhaust gas through the channels

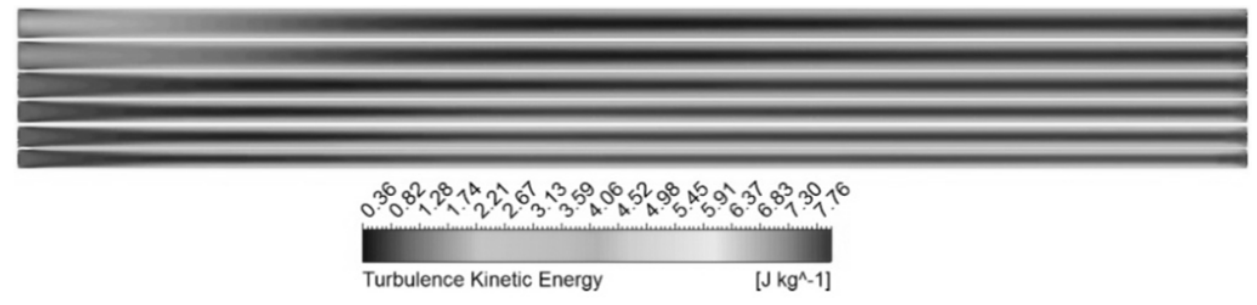

Rys. 6. Energia kinetyczna turbulencji w modelowanych kanałach

Fig. 6. Turbulent kinetic energy in modeled channels

\section{Podsumowanie}

Numeryczne obliczenia przepływu dla wybranych wielkości kanałów są pierwszym etapem budowy modelu redukcji $\mathrm{NO}_{\mathrm{x}}$ ze spalin bloków węglowych. Wyniki obliczeń zilustrowane $\mathrm{w}$ rozdziale 2.2. świadczą o wpływie średnicy kanałów katalizatora na przepływ strugi spalin. Można zauważyć znaczną zmianę ciśnienia wzdłuż kanałów, co przekłada się na wzrost prędkości przepływu spalin w zależności od średnicy modelowanych przewodów. Energia kinetyczna turbulencji tylko miejscowo wykazuje wyższe wartości. Należy zauważyć, że dla kanałów o największych szerokościach występuje dłuższa strefa stabilizacji strugi spalin. Może to mieć istotny wpływ na przebieg reakcji zachodzących na powierzchni katalizatora, a tym samym na wydajność procesu redukcji tlenków azotu ze spalin.

\section{Literatura}

[1] ANSYS® Fluent, Academic Research, Release 14.0.

[2] Baczyk M., Żupa P.: Wpływ redukcji emisji tlenków azotu opartych na metodach pierwotnych i wtórnych na pracę bloku energetycznego, Energetyka, 11 (2010) 733 738.

[3] Casagrande L., Lietti L.: SCR of $\mathrm{NO}$ by $\mathrm{NH}_{3}$ over $\mathrm{TiO}_{2}$-supported $\mathrm{V}_{2} \mathrm{O}_{5}-\mathrm{MoO}_{3}$ catalysts: reactivity and redox behavior, Applied Catalysis, 22 (1999) 63-77. 
[4] Dyrektywa 2010/75/UE z dnia 24 listopada 2010 roku w sprawie emisji przemysłowych (IED).

[5] Fulczyk T.: Wpływ dodatku kwasu cytrynowego na charakterystyki mokrej instalacji odsiarczania spalin, Praca doktorska, Gliwice 2013.

[6] Hilber M., Thorwarth H.: Lab-scale assessment of different parameters influencing the operational behaviour of SCR-DENOX-catalyst, VGB PowerTech, 10/2012.

[7] Informacja Zespołu realizacyjnego Tauron Wytwarzanie, Elektrownia Łaziska 2012.

[8] Raport z Projektu strategicznego VI.1.5.: Badania wpływu rodzaju technologii odazotowania na strukturę integracji instalacji cieplnej $\mathrm{z}$ procesem wychwytu,obejmujący zarówno studia dla kotłów pyłowych jak i fluidalnych, Gliwice 2013.

[9] Rozporządzenie Ministra Środowiska z dnia 22 kwietnia 2011 r. w sprawie standardów emisyjnych z instalacji Dz.U. 2011 Nr 95 poz. 558.

[10] Rummenhohl V., Capozella D.: Advanced selective catalytic reduction (ASCR) technology - A lower capital cost solution for $\mathrm{NO}_{\mathrm{x}}$ reduction, Power-Gen, Vienna 2013.

[11] Wielgosiński G.: Emisja tlenków azotu - istotny problem, Nowa Energia,1 (2012) 66-79.

\title{
NUMERICAL MODELING OF EXHAUST GASES DENITRIFICATION BY SCR METHOD
}

\begin{abstract}
S u m m a r y
Due to the introduction in 2016 the new standards for emissions of nitrogen oxides $\left(\mathrm{NO}_{\mathrm{x}}\right)$, there is a need to examine the possibility of using the technology of selective catalytic reduction (SCR) as a supplement to the primary methods. The use of a catalyst as an additional module purifying exhaust gases from $\mathrm{NO}_{\mathrm{x}}$ allows to extend the operation time of coal-fired plants according to IED directive. Reduction of nitrogen oxides from exhaust gases occurs by injection of reagent (ammonia, ammonia water) in the gas channel. $\mathrm{NO}_{\mathrm{x}}$ conversion is proceeding on the catalyst surface. This work is based on modeling the exhaust gas flow through the channels of different geometry by an Ansys Fluent code. This is the first step of creating a complete CFD model for the SCR technology, in which the influence of size of catalyst channels on the exhaust gas flow is considered.
\end{abstract}

Keywords: geometry of channels, catalyst, CFD model, reduction of $\mathrm{NO}_{\mathrm{x}}$

DOI: $10.7862 / \mathrm{rm} .2014 .17$

Otrzymano/received: 15.05 .2014

Zaakceptowano/accepted: 27.05.2014 